\title{
«RHR (Réforme Humanisme Renaissance)», n. 73
}

\section{Maurizio Busca}

\section{(2) OpenEdition}

\section{Journals}

\section{Edizione digitale}

URL: https://journals.openedition.org/studifrancesi/3047

DOI: 10.4000/studifrancesi.3047

ISSN: 2421-5856

\section{Editore}

Rosenberg \& Sellier

\section{Edizione cartacea}

Data di pubblicazione: 1 juillet 2013

Paginazione: 441-442

ISSN: 0039-2944

\section{Notizia bibliografica digitale}

Maurizio Busca, ««RHR (Réforme Humanisme Renaissance)», n. 73», Studi Francesi [Online], 170 (LVII | II) | 2013, online dal 30 novembre 2015, consultato il 02 février 2023. URL: http://

journals.openedition.org/studifrancesi/3047 ; DOI: https://doi.org/10.4000/studifrancesi.3047

\section{Questo documento è stato generato automaticamente il 2 février 2023.}

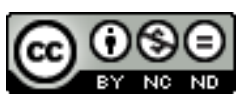

Creative Commons - Attribuzione - Non commerciale - Non opere derivate 4.0 Internazionale - CC BY NC-ND 4.0

https://creativecommons.org/licenses/by-nc-nd/4.0/ 


\title{
«RHR (Réforme Humanisme Renaissance)», n. 73
}

\author{
Maurizio Busca
}

\section{NOTIZIA}

«RHR (Réforme Humanisme Renaissance)», n. 73, décembre 2011, pp. 214.

1 Nel 1559 la libera traduzione di sei novelle di Matteo Bandello, ad opera di Pierre Boaistuau, col titolo di Histoires tragiques, segna convenzionalmente la nascita di un nuovo genere letterario, quello dell'histoire tragique appunto, che riscuoterà un successo considerevole nei decenni seguenti fino a tutta la prima metà del Seicento. Prendendo atto del crescente interesse della critica per i testi riconducibili a questo genere, l'Association d'études sur la Renaissance, l'Humanisme et la Réforme dedica una raccolta di studi alle histoires tragiques apparse tra il 1559 e il 1644, anno di pubblicazione dell'ultima raccolta di Jean-Pierre Camus. La presente miscellanea riunisce undici contributi, organizzati secondo un ordine metodologico e cronologico: i primi tre affrontano il problema della definizione del genere e ne studiano i rapporti con altri generi letterari coevi; nei quattro saggi seguenti gli autori si concentrano sulle raccolte cinquecentesche di Boaistuau, Belleforest e Poissenot, mentre negli ultimi quattro sono prese in esame le raccolte secentesche di Rosset e Camus. I contributi raccolti sono i seguenti: Estelle ZIERCHER, Histoires tragiques et formes narratives au XVI siècle, pp. 9-21; Nicolas LE CADET, Les "piteuses histoires» de l'“Heptaméron" et les histoires tragiques du XVI siècle, pp. 23-39; Philippe de LAJARTE, Types de récits et formes du tragique dans les recueils d'histoires tragiques de la seconde moitié du XVI e siècle et du début du XVII siècle, pp. 41-55; Bénédicte BOUDOU, Formes et représentations de l'intériorité dans les "Histoires tragiques" de Pierre Boaistuau, pp. 57-72; Jean-Claude ARNOULD, De Pierre Boaistuau à François de Belleforest, la rupture dans la "Continuation", pp. 73-87; Witold PIETRZAK, Les histoires tragiques de François de Belleforest et leur réception en France aux XVI et XVII siècles, pp. 89-106; Tamara VALC`IC'BULIC', Le narrateur de Poissenot, ou l'art de «tournoyer autour du 
pot», pp. 107-118; Jean-Raymond FANLO, Du rituel au procès: l'affaire Gaufridy dans l'“Histoire admirable" de Michaëlis et dans les "Histoires tragiques" de François de Rosset, pp. 119-130; Claire ESNAULT, Les scènes de supplice dans les "Histoires mémorables et tragiques" de François de Rosset, pp. 131-141; Magda CAMPANINI, Actualité et fabrication du tragique chez François de Rosset. Les variantes des deux premières éditions des "Histoires tragiques", pp. 143-161; Anna Karolina DUBoIs, La conception du tragique dans les récits brefs de Jean-Pierre Camus, pp. 163-177. Se nel primo gruppo di saggi viene messa in luce la complessità di un genere che presenta una ricca varietà strutturale e formale - varietà dalla quale dipende la difficoltà di stabilire caratteri costanti che definiscano e identifichino le histoires tragiques - la ricchezza e l'eterogeneità interne al corpus appaiono evidenti anche negli otto saggi monografici, nei quali gli autori affrontano problematiche di diversa natura (stilistica, retorica, tematica, ideologica, politica, filologica), rilevando, in particolare, la permeabilità del genere a molteplici influenze, dall'exemplum alla novella al romanzo sentimentale, passando attraverso studi di storiografia e di tragedia. 